\title{
Behavior of CAD/CAM ceramic veneers under stress: A 3D holographic study
}

\author{
J.-C. Durand ${ }^{\mathrm{a}, \mathrm{b}, *}$, P. Slangen ${ }^{\mathrm{c}}$, S. Montresor ${ }^{\mathrm{d}}$, A. Desoutter ${ }^{\mathrm{a}}$, O.Y. Solieman ${ }^{\mathrm{a}}$, M. Fages ${ }^{\mathrm{a}, \mathrm{b}}$, \\ P. Picart ${ }^{\mathrm{d}}$
}

${ }^{a}$ Laboratoire Bioingenierie et Nanosciences, LBN UR-UM104, Université de Montpellier, 545 Avenue du Professeur Jean Louis Viala, 34193, Montpellier Cedex 5, France ${ }^{\mathrm{b}}$ Department of Prosthetic Dentistry, Faculty of Odontology, Montpellier University, 545 Avenue du Professeur Jean Louis Viala, 34193, Montpellier Cedex 5, France ${ }^{\mathrm{c}}$ EuroMov Digital Health in Motion, Univ Montpellier, IMT Mines Ales, Ales, France

${ }^{\mathrm{d}}$ Le Mans Université, CNRS UMR 6613, LAUM, Avenue Olivier Messiaen, 72085, Le Mans Cedex 9, France

\section{A B S T R A C T}

Objectives: Ceramic veneers restorations may undergo damages, such as cracks, fractures, or debonding. Full-field measurements must be carried out in order to visualize and analyze the strain fields. This paper demonstrates that digital holography permits to investigate the mechanical behavior under stress of a natural incisor and a natural incisor reconstructed with CAD/CAM ceramic veneer.

Methods: The facial surface of a maxillary central incisor is prepared to receive a monolithic ceramic reconstruction manufactured using a chairside computer-aided design and computer aided manufacturing (CAD/CAM) system (Cerec AC ${ }^{\circ}$ system, Sirona Dental System ${ }^{\circledR}$, Bensheim, Germany). One incisor is kept intact for comparison. The samples are sectioned longitudinally to obtain a planar observation of the region of interest. A mechanical indentation head and digital holographic set-ups permit a full-field, contact-less and single-shot measurement of the three-dimensional displacement fields at the surface of the tooth sample when subjected to load. Stain fields are then estimated and comparison of the results between two samples can be carried out. Results: 3D displacement, fields and strain fields are measured and highlight the behavior of the region of interest in three directions of space for the ceramic veneer and the natural incisor. The strain maps reveal the local behavior, especially the concentration or the sudden change in strain. The transition zones are clearly observed, particularly for the veneered sample.

Conclusion: Digital holography highlights the localization of stress concentration zones in regions of interest and yields comparative analysis between samples with different tooth preparations.

Significance: holography permits to visualize and compare the mechanical response of the ceramic veneer and natural tooth. This helps choosing the mechanical properties of the bonding interface.

\author{
Keywords: \\ Holography \\ Ceramic veneer \\ 3D displacement fields \\ Dentin-ceramic junction \\ Mechanical behavior
}

\section{Introduction}

Owing to an increased demand for esthetics and high biocompatibility, all-ceramic restorations have become increasingly important in modern dentistry. The treatment of choice should be the least invasive option that achieves the expected esthetic and functional objectives (Freydberg, 2011). The last 30 years (Peumans et al., 2000) have seen the introduction of the ceramic laminate veneer (CLV), which aims at improving the shape, alignment, and color of teeth, and fulfilling the increasing demands for improved dental esthetics. In earlier cases, an esthetic outcome and long-term durability of treatment were achieved at the cost of extensive tooth preparation to accommodate the ceramic veneers, consequently reducing the thickness of teeth. CLV bonded to enamel was first introduced in the early 1980s (Calamia, 1983; Horn, 1983 ) as an esthetic restoration that requires minimal tooth preparation and as an alternative to full veneers (Gür and Kesim, 2004).

However, these restorations may undergo damages, such as cracks, fractures, or debonding. The three common types of CLV failure are

\footnotetext{
* Corresponding author. Université de Montpellier, Faculté d'Odontologie, 545 avenue du Professeur Jean Louis Viala, 34193, Montpellier Cedex 5, France.

E-mail addresses: jean-cedric.durand@umontpellier.fr (J.-C. Durand), pierre.slangen@mines-ales.fr (P.Slangen), sylvio.montresor@univ-lemans.fr (S. Montresor),

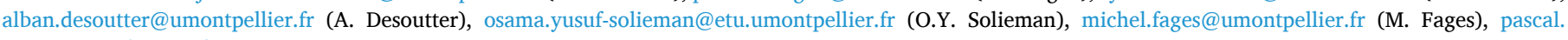
picart@univ-lemans.fr (P. Picart).
} 
static, cohesive, and adhesive fractures. Static fracture is defined as the fracture of a veneer fragment, while the remainder of the veneer remains intact on the tooth. Cohesive fracture is characterized by the loss of a piece of porcelain because of excessive functional or parafunctional load. In adhesive failure, the intact porcelain veneer completely debonds from the tooth (St Germain and St Germain, 2015). The form of preparation, the covering material and the method of assembly influence the mechanical properties of the reconstruction and thus the type of damage. Advances in dental computer-aided design and computer-aided manufacturing (CAD/CAM) (Patel, 2014) have catalyzed the development of esthetical ceramic restorations with improved mechanical properties (Sasse et al., 2015; Zahran et al., 2008). From a mechanical point of view, the possibility to program the thickness of the bonding joint, which is associated with precision machining, optimizes stress accommodation by the ceramic (Gür and Kesim, 2004). However, the mechanical properties of reconstruction and assembly materials seem to be the essential factor for success (Fages et al., 2017). Bonding agents must be selected very carefully because they determine not only the adhesion but also the ultimate strength of CLV (Addison et al., 2010; Attia and Kern, 2004; Barak et al., 2009; Guarda et al., 2010).

Thus, further studies are recommended to investigate the stress accommodation properties of bonded ceramic restorations (Gür and Kesim, 2004). In the past, researchers have developed and used different methodologies to evaluate the properties of dental reconstructions. Methods of experimental validation and 3D finite element analysis of interface problems in adhesive reconstructions are still regularly used to reveal differences in tensile and compressive stresses in reconstruction materials and interfaces (Archangelo et al., 2011; Ereifej et al., 2011; Magne and Douglas, 1999a; Meredith et al., 1996; Silva et al., 2006; Zheng et al., 2012). However, this approach requires contact between the measuring device and the biological material. In order to obtain a contact-less and full-field inspection of the behavior of dentin or enamel, optical metrology was developed (Asundi and Kishen, 2001, 2000a, 2000b; Kishen and Asundi, 2007, 2002, 2001; Kishen et al., 2006, 2000; Shahar and Weiner, 2007; Wang and Weiner, 1998; Wood et al., 2003; Xu et al., 1998; Zaslansky et al., 2005). Moiré projection and digital photo elasticity provide images of the inspected surface through observation of fringe patterns encoding the changes at the surface of the sample (Asundi and Kishen, 2001, 2000a, 2000b; Kishen and Asundi, 2007, 2002, 2001; Kishen et al., 2006, 2000; Shahar and Weiner, 2007; Wang and Weiner, 1998; Wood et al., 2003). However, these techniques require surface preparation by bonding a specific revealing material. Coherent metrology based on phase-shifting electronic speckle pattern interferometry (ESPI), overcomes such requirements by directly illuminating the surface of the sample using laser light (Barak et al., 2006; Zaslansky et al., 2005; Kumar et al., 2016; Ormenisan et al., 2017). Although the tooth surface may be slightly painted to enhance the signal-to-noise ratio, no specific material bonding is needed. ESPI can provide full-field measurements of the three-dimensional (3D) displacement at the surface of the sample. Such full-field analysis is useful for comparison using FEM analysis (Fages et al., 2012; Guarda et al., 2010; Lev-Tov Chattah et al., 2009) because it provides a high density of data points. However, this measurement technique is not "single-shot" because the displacement components have to be measured sequentially; this does not guarantee immunity to mechanical or environmental drifts. Alternatively to these approaches, coherent imaging with digital holography is a method that can yield simultaneous 3D displacement fields at the surface of any sample (Picart, 2015). Recent advances demonstrated that digital holography can be also applied at different scales, from millimeter scale to meter scale in difficult and perturbed environments (Khodadad et al., 2015; Pedrini et al., 2019; Fratz et al., 2019). In order to simultaneously measure the 3D displacement field at the surface of the sample, this paper proposes an experimental approach based on digital three-color holography that yields simultaneous measurements of the 3D displacement field at the surface of the studied samples. This opens the way for direct observation of the mechanical behavior of the ceramic under stress. The goal of this paper is thus to visualize and analyze the performances of the CLV under stress by observing the behavior of the ceramic, the bonding joint and the dental support and to compare them with the behavior of the natural tooth and especially the dentine-enamel junction (DEJ). From these observations, the main regions of interest (ROI) can be highlighted to discuss what factors may be responsible for the sustainability of these reconstructions. In this paper, a natural tooth and a tooth reconstructed with CLV were subjected to mechanical loads and investigated using digital color holography. Longitudinally cut sections of samples permit to achieve a planar object observation and to look "inside" the tooth (Fig. 1) simultaneously in three directions of space. Measurement of the general behavior of the two samples of different nature is provided in order to observe and compare the stress concentration areas in regions of interest.

The paper is organized as follows: section 2 presents the materials and methods, section 3 gives the experimental results and section 4 provides discussions. Section 5 draws the conclusion of the paper.

\section{Materials and methods}

\subsection{Specimen preparation}

Two extracted (for periodontal reasons) caries-and restoration-free human maxillary central incisors were used. The teeth samples are disinfected and stored in physiological serum with traces of chloroform. One incisor was kept intact and the other was prepared with a chamfer finish line (Hong et al., 2017) to receive a CLV. CLV is fabricated using a chairside Cerec AC ${ }^{\circledR}$ CAD/CAM system (Dentsply Sirona, Sirona Dental System ${ }^{\circledR}$, Bensheim, Germany) unit running under 4.2 software (Nejatidanesh et al., 2018). This system is composed of two distinct units: an optical imprint recorder that allows the CAD, and the milling unit (CAM) that uses the CAD data to manufacture the restoration out of a ceramic block. The software is programmed to provide dento-prosthetic spacing, peripheral joint thickness, and veneer thickness of respectively $100 \mu \mathrm{m}$, $40 \mu \mathrm{m}$, and $600 \mu \mathrm{m}$. Optical imprints of the prepared tooth are recorded and the machine (Cerec MC ${ }^{\circledR}$, Dentsply Sirona, Sirona Dental System ${ }^{\circledR}$, Bensheim, Germany) milled the veneer. The Vita MarkII ${ }^{\circledR}$ (Vita Zahnfabrik, Bad Säckingen, Switzerland) ceramic blocks composed of albite-enriched feldspathic ceramic were used. After milling, the extrados are glazed using Azkent ${ }^{\circledR}$ (Vita Zahnfabrik, Bad Säckingen, Switzerland). The CLV are bonded onto the prepared tooth using RelyX ${ }^{\mathrm{TM}}$ Unicem Aplicap ${ }^{\mathrm{TM}}$ capsule (3M ESPE Dental Division, St. Paul, MN, USA) following the standard clinical protocol of illumination for $4 \mathrm{~s}$ at $3000 \mathrm{~mW} / \mathrm{cm}^{2}$ with a Swissmaster Light ${ }^{\circledR}$ lamp (E.M.S, Nyons, Switzerland).

As shown in Fig. 2, the tooth, that was kept intact, is sectioned longitudinally in two parts in the vestibular-lingual direction and one of the two resulting parts is removed with a diamond disc (Isomet 2000 Bueler, LakeBluff, IL USA). Longitudinal sectioning was used to allow planar observation and appreciate the different behaviors inside the tooth i.e., the natural DEJ and the dentin cementum junction (DCJ). The sectioned tooth is then cemented onto the sample holder with a layer of Sintofer ${ }^{\circledR}$ (Hunstman Advanced Materials, The Woodlands, Texas, US). Sample holders are machined in chromium cobalt to achieve a rigidbody unit that can comply with the loading system.

\subsection{Load system}

The load system is illustrated in Fig. 3. The compression test device is adapted to the high sensitivity of 3D holography and copes with parasitic movements of the whole system. The sectioned tooth cemented on the sample holder was placed under a force transducer (Model 31, Honeywell International, Morriston, NJ, USA). This mid-range precision miniature load cell is slowly translated vertically by the motor $(M-235 \AA$, PI. Karlsruhe, Germany). The system can generate a force-driven 


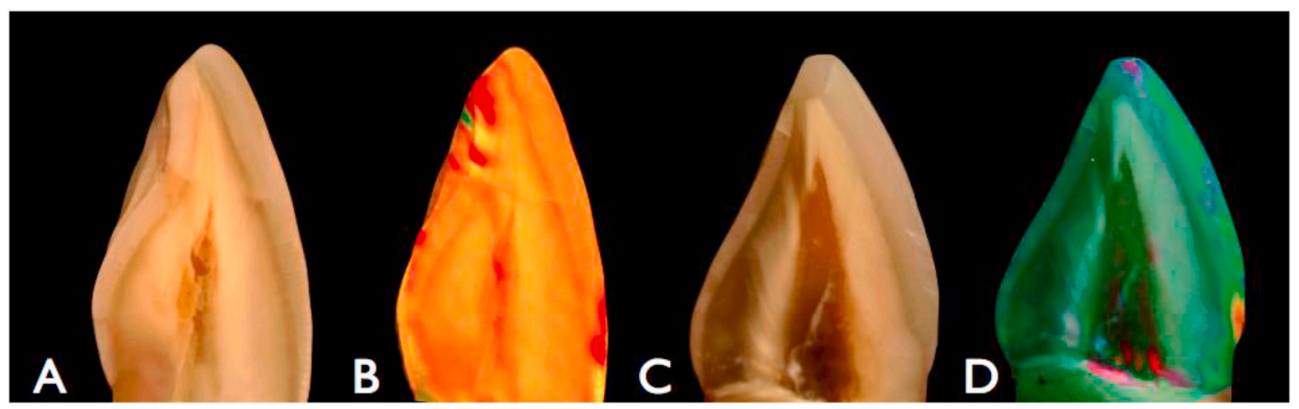

Fig. 1. Natural tooth (A) and natural tooth with a 3D holography projection (B), Tooth with laminate veneer (C), and tooth with laminate veneer and 3D holography projection (D).

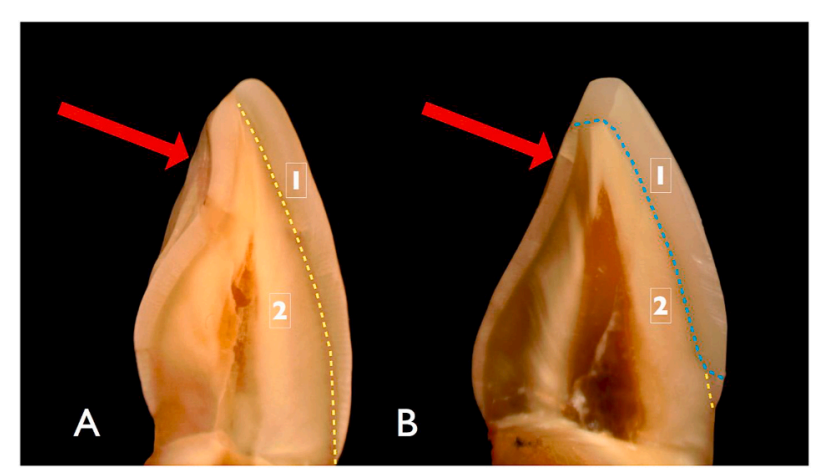

Fig. 2. Photographs of samples prepared for experimentation. (A) natural tooth, (B) tooth with CLV. The yellow line indicates the dentin-enamel junction, the blue line the glue junction. One (1) A indicate enamel, 1B the CLV. The number 2 indicates dentin for both samples A and B. The red arrow indicates the application of the load force.

displacement (C-862 Mercury PI, Karlsruhe, Germany) or a user-defined displacement. The compression apparatus communicates with the computer through NI USB-6251 (National Instruments, Austin, TX, USA) and is interfaced with an in-house LabVIEW program (National Instruments, Austin, TX, USA). The force can be applied to the tooth directly using a force transducer or a relay rod. We applied the force to the palatal surface of the tooth, as shown in Fig. 3. Preliminary testing by 3D holography showed good performance of the mechanical set-up without any spurious displacements. The entire mechanical system was clamped onto the holographic tabletop. Theoretically, this system can achieve small displacement steps of $1.6 \mathrm{~nm}$. The increment of $3.3 \mu \mathrm{m}$ is selected for this study. That means that the setpoint on the motor is the displacement increment of the mechanical head rather that the force increment.

\subsection{Digital holographic set-up}

The digital holographic set-up is based on a three-color holographic scheme of the Fresnel configuration (no lens between sample and sensor) and is described in Fig. 4.

The laser beams, emitted from continuous diode pumped solid state lasers, yield red line (R), green line (G), and blue line (B) at wavelengths $\lambda_{R}=660 \mathrm{~nm}, \lambda_{G}=532 \mathrm{~nm}$, and $\lambda_{R}=457 \mathrm{~nm}$, respectively. The three laser beams are shaped independently before being recombined to generate three-color digital holograms. This shaping is done primarily to obtain a reference wave consisting of the superposition of the three laser lines, and secondly to obtain three different illumination beams propagating along different directions before illuminating the surface of the sample. Dichroic plates (D1 and D2) permit to mix the three reference beams to produce a single three-color beam. Along the reference path, three smooth plane reference waves were produced through the spatial filter (SF; $\times 20$ microscope lens and $20 \mu \mathrm{m}$ pinhole) and the achromatic lens (AL). The $50 \%$ beam splitter cube reflects the reference beams onto the sensor area. Note that the light beams (reference and probe beams) were co-polarized to enable interferences at the sensor plane. The

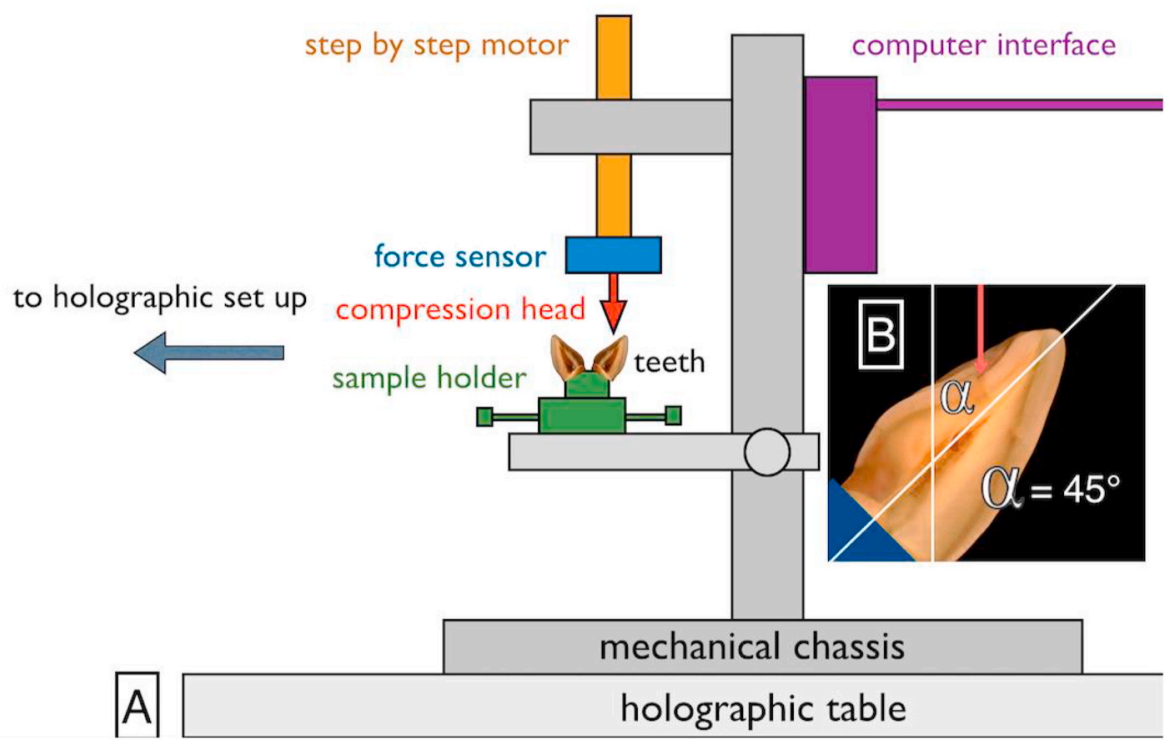

Fig. 3. 3A. Mechanical set-up. 3B: the load force (red arrow) is applied on the palatal face and oriented in the $\mathrm{Y}$ axis, at $45^{\circ}$ to the major axis of the tooth. 


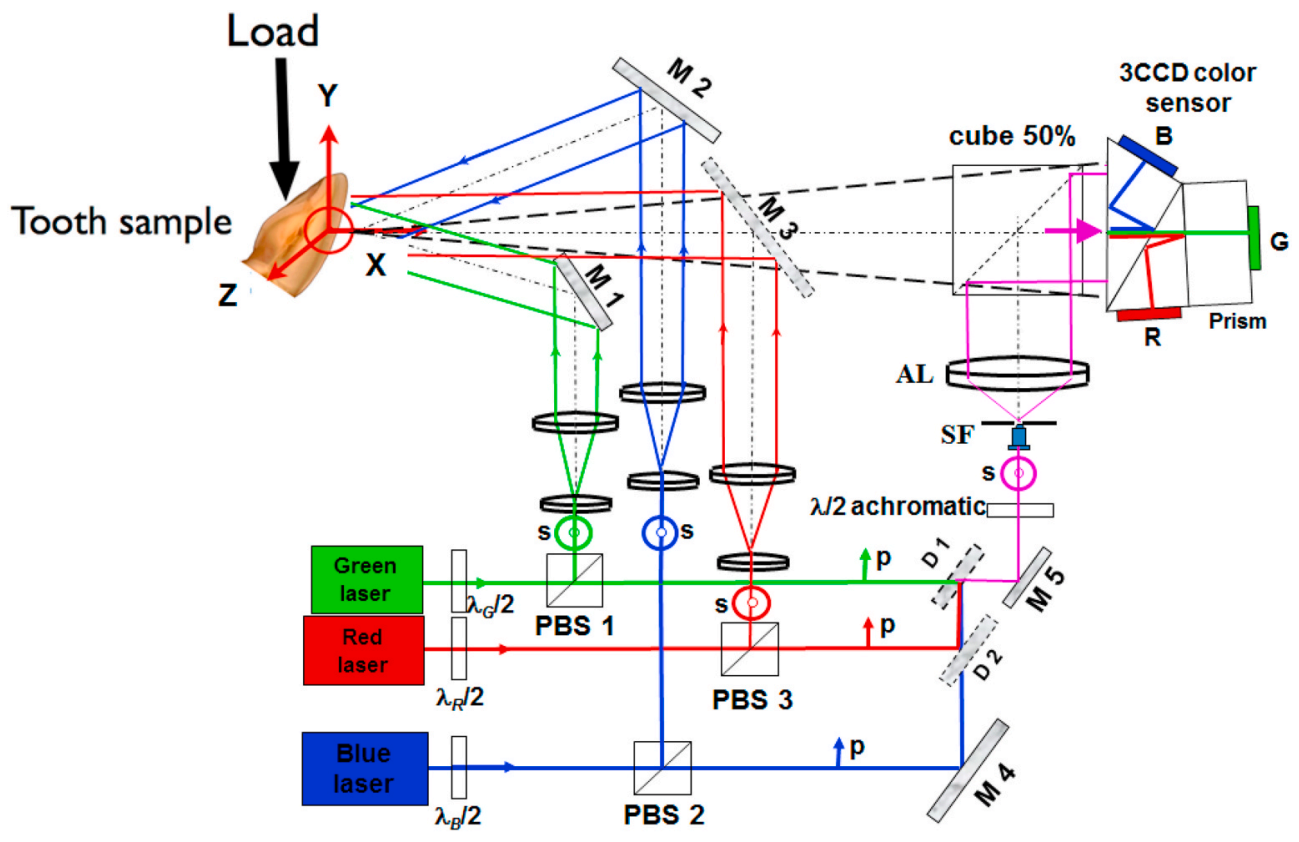

Fig. 4. Digital holographic set-up: PBS1-3: polarizing beam splitter, D1-2: dichroic plate, M1-5: mirrors, AL: achromatic lens, SF: spatial filter.

reference beam impacts the sensor with a slight tilt angle to generate offaxis holographic recording. C7780-20 color sensor (Hamamatsu Photonics K.K., Hamamatsu City, Shizuoka, Japan) was used that includes $M \times N=1024 \times 1344$ pixels with pixel pitches at $p_{x}=p_{y}=6.45 \mu \mathrm{m}\left(p_{x}\right.$, $p_{y}$ : pixel pitches along the horizontal and vertical directions of the sensor plane) and 8-bit digitization. In order to measure the 3D displacement fields at the surface of the object, the three illumination beams must have distinct incidence angles. In the set-up, the B and $\mathrm{G}$ beams are included in the $\{x, z\}$ plane, whereas the R beam is included in the $\{y, z\}$ plane (Fig. 4). The incidence angles were measured at $\theta_{y z}^{G}=\theta_{y z}^{B}=\theta_{x z}^{R}$ $=0, \theta^{G}=-31.3^{\circ}, \theta_{x z}^{B}=+34.6^{\circ}$, and $\theta_{x z}^{R}=-14^{\circ}$. The illuminated area was around $9.2 \mathrm{~mm} \times 9.2 \mathrm{~mm}$. The sample is placed at a distance of $d_{0}=700 \mathrm{~mm}$ from the sensor area and submitted to compression using the mechanical system. Fig. 5 shows photographs of the experimental set-up.

\subsection{Digital hologram processing}

The sensor can fully separate the three colors by using a dichroic prism facing the pixel matrix. Thus, each monochrome hologram can be numerically reconstructed independently. If $O$ and $R$ represent the wave front from the illuminated object and the reference wave, respectively, then each monochrome digital hologram $(\mathrm{H})$ can be expressed in the form of Eq. (1) (Schnars and Jüptner, 1994).
$H=|R|^{2}+|O|^{2}+R^{*} O+R O^{*}$

The illuminated object surface is at a distance $d_{0}$ from the recording sensor. The object wave diffracted to the sensor plane can be expressed with the Fresnel approximations by Eq. (2) (Goodman, 1996; Picart and Leval, 2008) $(i=\sqrt{ }-1)$ :

$$
\begin{gathered}
O\left(x, y, d_{0}\right)=-\frac{i}{\lambda d_{0}} \exp \left(\frac{2 i \pi d_{0}}{\lambda}\right) \exp \left(\frac{i \pi}{\lambda d_{0}}\left(x^{2}+y^{2}\right)\right) \\
\times \iint A(X, Y) \exp \left(\frac{i \pi}{\lambda d_{0}}\left(X^{2}+Y^{2}\right)\right) \exp \left(-\frac{2 i \pi}{\lambda d_{0}}(x X+y Y)\right) d X d Y .
\end{gathered}
$$

In Eq. (2), the object wave front at the object plane is $A(X, Y)=A_{0}(X$, $Y) \exp \left[i \psi_{0}(X, Y)\right], \lambda$ is the wavelength of light, $A_{0}$ is related to the object reflectance, and $\psi_{0}$ is the optical phase related to the object surface profile and roughness. From digitally recorded holograms, the reconstruction of the object field at any distance $d_{r}$ from the recording plane is given by the discrete Fresnel transform (Schnars and Jüptner, 1994). From the hologram, the numerically reconstructed complex-valued image can be obtained from Eq. (3) (Picart and Leval, 2008; Schnars and Jüptner, 1994):

$A_{r}=h_{F} \times F F T\left[H \times h_{F}\right]$,

where FFT means a two-dimensional fast Fourier transform and $h_{F}$ is the
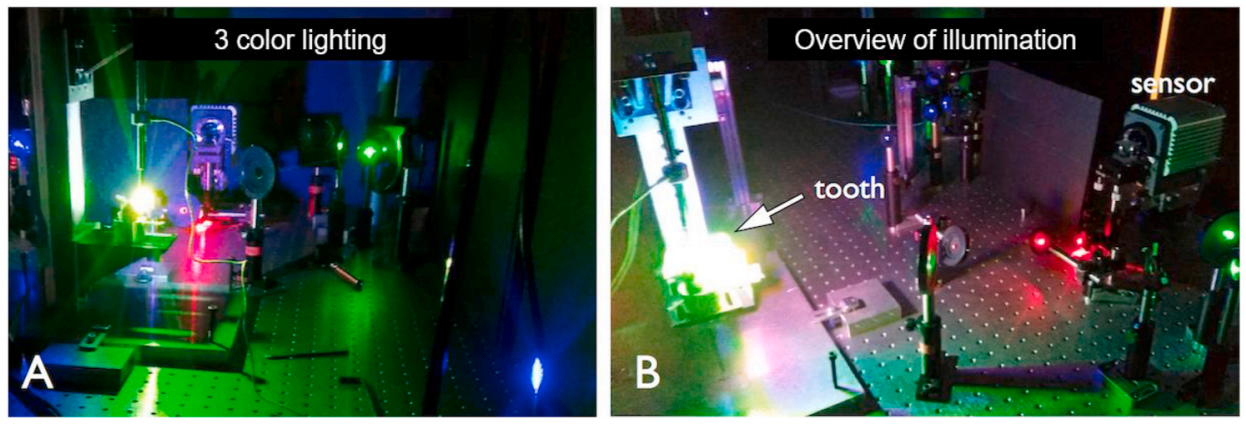

Fig. 5. Photographs of the experimental set-up: A) Photograph of the three-color lines. (B) Photograph of the lasers illuminating the sample. The R-G-B laser spots produce a white light spot at the sample surface. The white light beam diffracted from the sample surface propagates to the sensor plane to generate interferences by coherent mixing with the reference beam (not visible on the photograph). 
Fresnel kernel defined by Eq. (4),

$h_{F}(x, y)=\frac{1}{\sqrt{\lambda d_{r}}} \exp \left(i \pi \frac{d_{r}}{\lambda}-i \frac{\pi}{4}\right) \exp \left[\frac{i \pi}{\lambda d_{r}}\left(x^{2}+y^{2}\right)\right]$.

From the numerical computation of Eq. (3) with each monochrome hologram, the amplitude and phase of the diffracted field $A_{r}$ can be calculated. When the reconstruction distance is $d_{r}=-d_{0}$, the initial object plane is recovered and the phase variation from the hologram sequence is related to the displacement field at the surface. When considering two consecutive recordings at two different mechanical loads, the phase variation is given by Eq. (5) (known as the Doppler phase):

$\Delta \phi=\frac{2 \pi}{\lambda} \mathrm{U} .\left(\mathrm{K}_{\mathrm{e}}-\mathrm{K}_{\mathrm{o}}\right)$.

In the set-up, $\mathbf{K}_{\mathbf{o}} \cong \mathbf{k}$ is the observation vector and $\mathbf{K}_{e}$ is the illumination vector (see Fig. 4) given by

$\mathrm{K}_{\mathrm{e}}^{\lambda}=-\cos \theta_{y z}^{\lambda} \sin \theta_{x z}^{\lambda} \mathrm{i}-\sin \theta_{y z}^{\lambda} \mathrm{j}-\cos \theta_{y z}^{\lambda} \cos \theta_{x z}^{\lambda} \mathrm{k}$

The phase change in Eq. (5) is related to the displacement field $\mathbf{U}$. Quantitative measurements at the surface of the tooth sample are carried out by a subtraction between the object phase and a "reference" phase. The phase in Eq. (5), is given modulo $2 \pi$ and phase unwrapping is then required (Ghiglia and Pritt, 1998; Xia et al., 2016).

\subsection{Displacement and strain calculation}

The numerical computation of the three monochrome holograms yields three different Doppler phases because the sample was illuminated using three different laser beams along three different illumination directions (see Eq. (5)). The 3D displacement field $\mathrm{U}\left\{\mathrm{U}_{\mathrm{x}}, \mathrm{U}_{\mathrm{y}}\right.$ and $\left.\mathrm{U}_{\mathrm{z}}\right\}$ at the sample surface can be extracted from these phase differences obtained along the three wavelengths (Tankam et al., 2010; Picart 2015). The set of phase data yields the individual displacement component of the 3D displacement field $\left\{U_{x}, U_{y}\right.$ and $\left.U_{z}\right\}$. The relationship between the 3D components and the phase data is given by Eq. (7):

$$
\left[\begin{array}{l}
u_{x} \\
u_{y} \\
u_{z}
\end{array}\right]=\frac{1}{2 \pi} \mathbf{M}_{\theta}^{-1} \times\left[\begin{array}{c}
\lambda_{R} \Delta \phi_{R} \\
\lambda_{G} \Delta \phi_{G} \\
\lambda_{B} \Delta \phi_{B}
\end{array}\right],
$$

with

$\mathbf{M}_{\theta}=\left[\begin{array}{lll}-\cos \theta_{y z}^{R} \sin \theta_{x z}^{R} & -\sin \theta_{y z}^{R} & -1-\cos \theta_{y z}^{R} \cos \theta_{x z}^{R} \\ -\cos \theta_{y z}^{G} \sin \theta_{x z}^{G} & -\sin \theta_{y z}^{G} & -1-\cos \theta_{y z}^{G} \cos \theta_{x z}^{G} \\ -\cos \theta_{y z}^{B} \sin \theta_{x z}^{B} & -\sin \theta_{y z}^{B} & -1-\cos \theta_{y z}^{B} \cos \theta_{x z}^{B}\end{array}\right]$

The superscripts R, G, and B indicate the data extracted from each individual red-green-blue (R-G-B) hologram. The measurements of $\left\{\mathrm{U}_{\mathrm{x}}\right.$, $\mathrm{U}_{\mathrm{y}}$ and $\left.\mathrm{U}_{\mathrm{z}}\right\}$ are used to compute the three strain fields $\left\{\varepsilon_{x x}, \varepsilon_{y y}\right.$, and $\left.\varepsilon_{x y}\right\}$. Therefore a moving kernel of $15 \times 15$ pixels is used to estimate the best slope, in the least square sense, in the displacement fields $\left\{U_{x}\right.$ and $\left.U_{y}\right\}$, along the $\mathrm{X}$ and $\mathrm{Y}$ directions. This approach guarantees a low noisesensitive computation. The first-order derivatives along $\mathrm{X}$ and $\mathrm{Y}$ are obtained by calculating the local slopes and then the three strain fields $\left\{\varepsilon_{x x}, \varepsilon_{y y}\right.$, and $\left.\varepsilon_{x y}\right\}$ are calculated using Eq. (9) (Feissel, 2012).

$$
\left\{\begin{array}{l}
\varepsilon_{x x}=\frac{\partial U_{x}}{\partial x} \\
\varepsilon_{y y}=\frac{\partial U_{y}}{\partial y} \\
\varepsilon_{x y}=\frac{1}{2}\left(\frac{\partial U_{x}}{\partial y}+\frac{\partial U_{y}}{\partial x}\right) .
\end{array}\right.
$$

\subsection{Experimental method}

Samples were white powdered using white paint to generate a uniform diffusing surface and avoid light modulations between dentin and enamel or ceramic and dentin. The starting load can be controlled at any force value. The compression is increased stepwise, performing discrete displacements of the transducer tip. Thus, the compression increases with the advancing steps. The load range applied to the different samples is between $1 \mathrm{~N}$ to $10 \mathrm{~N}$ and this requires to record 50 digital color holograms. The time required for the recording was almost $10 \mathrm{~min}$. The Charge-Coupled Device (CCD) camera records the three-color hologram at each step of load increment. Then, digital holograms are numerically reconstructed to obtain each individual R-G-B phase, and the Doppler phases are evaluated by calculating the phase differences. For each color channel, the phase difference is obtained by calculating the difference between the phase at any load step and that at the previous load step. These phase differences are filtered using the windowed Fourier transform (Kemao et al., 2005) to reduce the speckle decorrelation noise (Montresor and Picart, 2016). Then, the filtered Doppler phases are unwrapped (Xia et al., 2016). The first recorded hologram is considered as the reference state for each sample. The phase maps obtained between minimal and maximal loading values are stored in the computer. Displacement fields are then calculated from the phase differences using Eq. (7). The cumulated displacement is computed from the set of displacement fields obtained from each load step. Finally, the strain fields are calculated using the cumulated displacement fields. It is reported that digital holographic interferometry (Picart, 2015) provides a relative displacement measurement. So, the "reference state" could be any of the sets of recorded holograms.

\section{Results}

The results are presented in Figs. 6-11 for both the veneer and the natural tooth samples. Displacement fields and strain maps are given after computation from the digital color holograms, acquired at the same time for the same mechanical state of the object. The maximum load between the reference state and the last one is about $8 \mathrm{~N}$ with a pre-load of $1.5 \mathrm{~N}$ in order to put in position the sample. The load is applied increment by increment and this requires to record almost 50 digital holograms. Digital color holography yields quantitative displacement fields. Then, there is no specific requirement for any standardization of the results. As an important result, the 3D displacements are in the micrometer range, the scale bar of $2 \mathrm{~mm}$ in the figures provides the dimensions of the measured area. Figs. 6 and 7 give the in-plane components $\left(U_{x}\right.$ and $\left.U_{y}\right)$ and the out-of-plane component $\left(U_{z}\right)$ of the displacement fields obtained in the three directions after calculation from Eqs. (7) and (8). The dark-blue and dark-red colors in the colorbar correspond to the minimum and the maximum values, respectively.

The displacement fields do not have the same amplitude in the three directions of space. Fig. 6 (veneer maps) and Fig. 7 (natural tooth maps) show the global displacements (top A, B, and C), while bottom figures (A,' B, and C') show the total cumulated displacements corrected from the residual rigid body motion (average slope) for each component.

Note that removing the residual rigid body motion is mandatory in order to reveal fine discrepancies that could have been missed in the total cumulated displacement representations. Fig. 8 (veneer) and Fig. 9 (natural tooth) show the mixed displacement field represented in quiver mode i.e. arrows with components $\left(\mathrm{U}_{\mathrm{x}}, \mathrm{U}_{\mathrm{y}}\right)$ at each selected point (reduction factor of 1:10 both in $\mathrm{X}$ and $\mathrm{Y}$ directions, $\mathrm{A}$ is the full value $\mathrm{B}$ is the mean displacement). The length of the arrows is proportional to the length of the vector $\left(\mathrm{U}_{\mathrm{x}}, \mathrm{U}_{\mathrm{y}}\right)$. It is then possible to qualitatively observe the in-plane components aggregated together i.e., the differential behaviors of the natural tooth compared with those of the veneered natural tooth. Such a representation is useful for observing the overall movement of the tooth submitted to the indentation head. Displacements from the $U_{z}$ maps (Fig. 6C, C' and Fig. 7C, C') permit to 

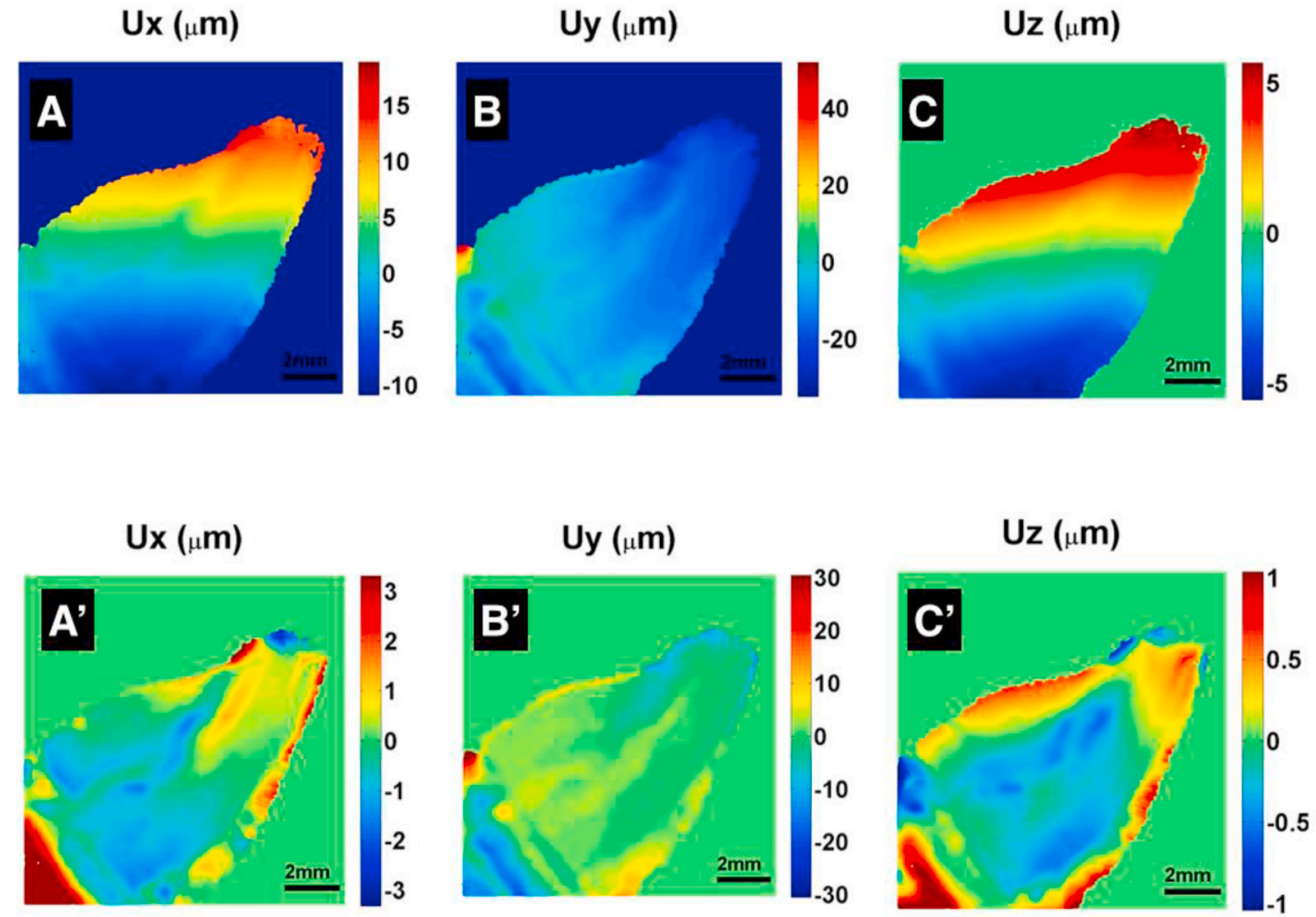

Fig. 6. Veneer. Displacements A, B, A,' and B': full-field displacements in the in-plane components. C and C': out-of-plane component. A, B, C, show global displacements, A,' B,' C' show the global displacements corrected from the average rigid body motion (i.e. the average slope over the field of view).

verify whether the load was generated, confirming that overall the indentation head and the holder devices were efficient for the experiments, because the out-of-plane rigid body motion is in the order of only few micrometers (refer to the color bar in Fig. 6C for example). From Fig. 7A and $\mathrm{C}$, the tooth sample is deformed by the load and undergoes clockwise rotation along the Z-axis, as shown by the red zone on the tip of the tooth. This is due to the contact between the indentation head and the tooth sample. The clockwise in-plane rotation is the combination of two slopes along the $\mathrm{X}$ and $\mathrm{Y}$ directions.

As a general rule, strains reveal the typical behavior of the studied structure. They are derived from Eq. (9) and the different strain fields $\varepsilon_{\mathrm{xx}}, \varepsilon_{\mathrm{yy}}$, and $\varepsilon_{\mathrm{xy}}$ are provided in Fig. 10 (veneer sample) and Fig. 11 (natural tooth sample). Compression strain is negative while tensile strain (or expansion) is positive. The generated compression and dilation are in opposition to the object holder.

These strain maps are given in $\mu \mathrm{m} / \mathrm{mm}$ units and reveal the local behavior, especially the concentration or sudden change of strain. This can be observed as an accommodation of the load or as a local accumulation of charge of the globally applied load. It is clearly visible in the transition zones and in particular at the veneer limits, as in Fig. 10B (for $\varepsilon_{x y}$ ) where the straight yellow-orange line from 10 to $15 \mu \mathrm{m} / \mathrm{mm}$ is oriented along the border. Table 1 and Table 2 summarizes the minimum, maximum, peak-to-valley, and standard deviations of the strain fields for both samples. Note also that the minimum and maximum of the scale bars in Figs. 10 and 11 have almost similar values for the veneer and the natural tooth.

For the veneer strains, Fig. 10 clearly shows the action on the tooth: $\varepsilon_{\mathrm{xx}}$ points out the tip of the veneer submitted to load with a local concentration of the strains, while $\varepsilon_{\mathrm{yy}}$ shows the shoulder effect in the lower right corner. The $\varepsilon_{\mathrm{xy}}$ map clearly shows the tooth-veneer junction and few shearing in the "empty" area of tooth preparation at the cervical margin (also observed in the other strain maps).

\section{Discussion}

If we consider the ROIs for the stress concentrations, we note for the natural tooth, the $\varepsilon_{\mathrm{xx}}$ map Fig. 11A clearly exhibits the tensile strain (in red) at the applied load point regarding the compression zone (in blue), at the other side of the tooth tip. Some sample holder effects are also observable in the bottom left corner in Fig. 11, showing compressive strain (red zone). This is also shown by the quiver plot (Fig. 9) with diverging streamlines in the bottom left corner of the natural tooth.

For the veneered tooth, the cervical limit is clearly revealed by the $\varepsilon_{\mathrm{xx}}$ and $\varepsilon_{\mathrm{xy}}$ strain maps (Fig. 10), as the activity is very high in this material transition zone. The same effect is also shown by the quiver plots for the veneer, in particular for the displacement in Fig. 8B. This transition is also included in the natural tooth in Fig. 9B. Due to the softness of DEJ, the transition zone is not as critical as in the tooth-veneer junction. This area is identified as a stress concentration zone (Fig. 11). Measurements with holography could be applied to investigate which form of cervical limit or which type of glue would accommodate at best the applied stress in this zone. The results confirm the study in the paper of Seymour et al. (Seymour et al., 2001) stating that a knife-edge finish is mechanically less stressful than a shoulder finish, since it does not act as a blockage, thereby initiating a stress concentration in this zone. In a physiological context, the veneers are not subjected to violent stresses such as shocks, but rather to a transmission of repeated stresses of more or less strong intensity from the palatal face (occlusion and mastication). These stresses inevitably induce a fatigue of the bonding joint and the geometry of the tooth preparation seems to have an impact on this fatigue. The results of holography allow locating the concentration zones of these stresses to compare them with the behavior of the natural tooth and the results obtained in previous studies.

Üstün and Öztürk (2018) used finite element analysis (FEA) to study different models of ceramic veneers. FEA is a simulative and numerical study that presents certain advantages over other observational approaches such as strain gauge or photo-elastic studies (Magne and 

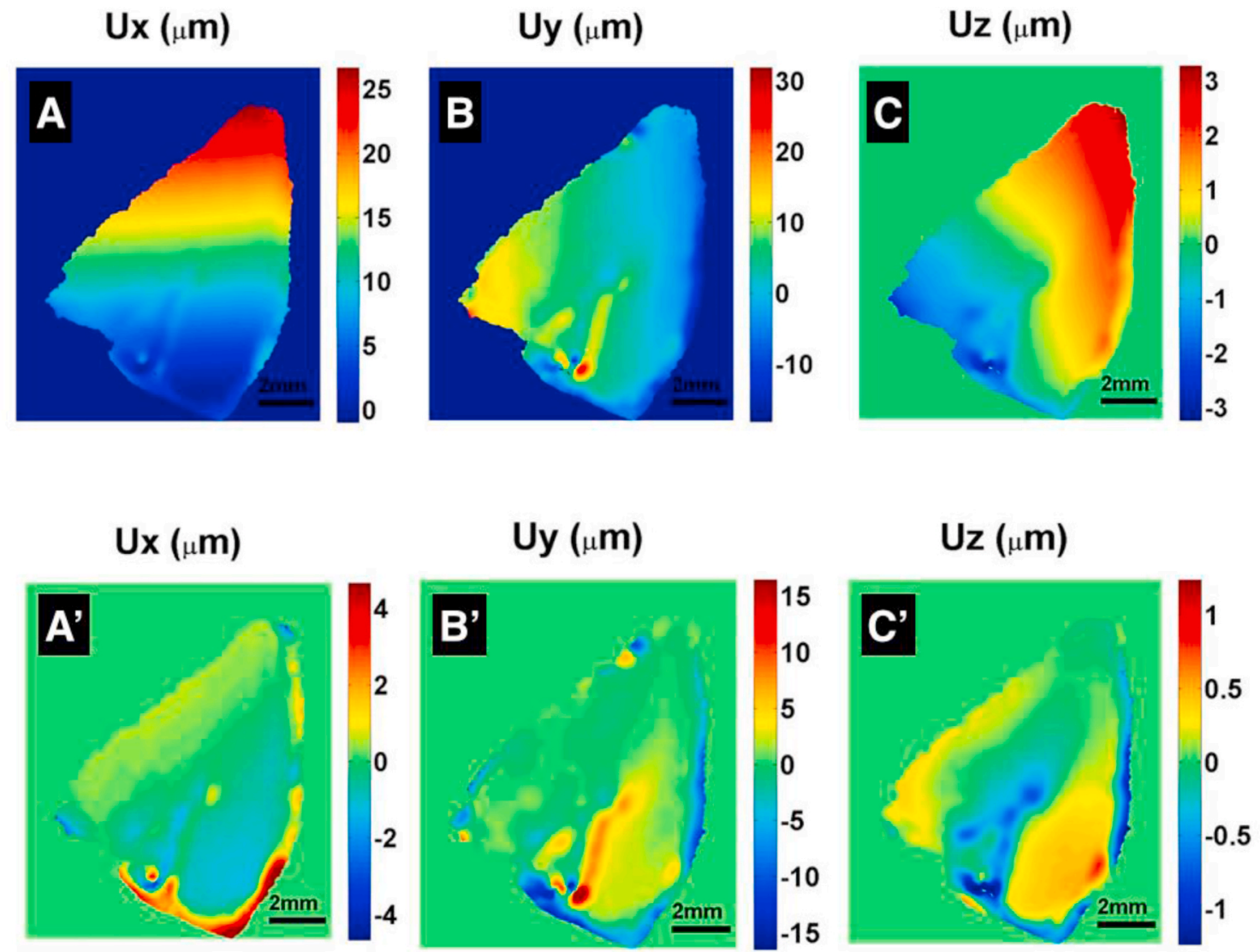

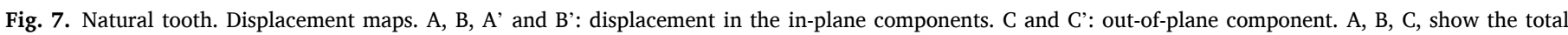
cumulated displacements; A,' B,' C' show the displacements fields with the rigid body motion removed.
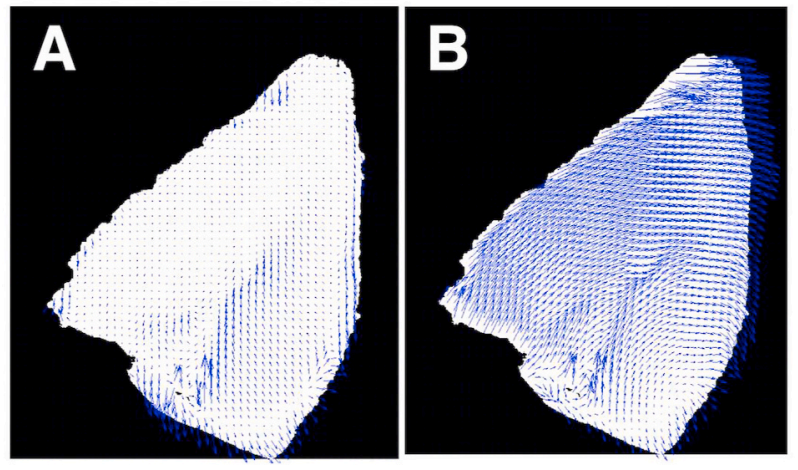

Fig. 8. Veneer: mixed displacement field represented in quiver mode as arrows with components (Ux and Uy) at each selected point with components (Ux and Uy) at each selected point after slope removal. A) total displacement, B) displacement without the rigid body motion.

Douglas, 1999b). It can be used to determine and represent the potential fracture areas and certain stress distribution patterns. Üstün and Öztürk (2018) reported that the maximum stress concentrations were observed at the ceramic veneer level. On the other hand, the stress distributions in the dental tissues were condensed in the incisal and cervical areas (Fig. $10 \mathrm{~A} \varepsilon_{\mathrm{xx}}$ ). It is a well-known fact that ceramic has a higher modulus of elasticity than that of the dental tissue and resin composite cement. In contrast, the cement layer behaves like a stress absorber. Despite the advantages of FEA, it is always necessary to feed the models with realistic boundary conditions. The literature highlights optical methods to assess dental behavior under stress (Picart et al., 2019). Optical

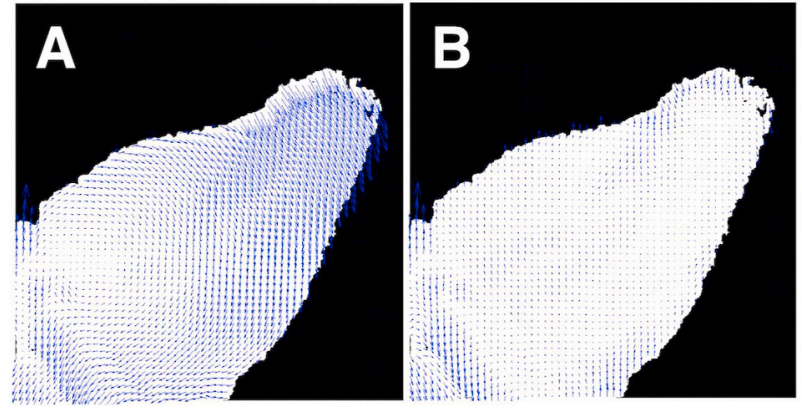

Fig. 9. Natural tooth. Mixed displacement field represented in quiver mode as arrows with components (Ux and Uy) at each selected point. A) total cumulated displacement, B) displacement without the rigid body motion.

techniques and holography can provide such data when recorded from real cases. Although the amount of data may be huge, it is still possible to reach the optimum data values. It is interesting to note that we observed some similarity in the results obtained in FEA technique and holography technique, highlighting similar activity zones for comparable experimental conditions (Fig. 8A and B and Fig. 10A: $\varepsilon_{\mathrm{xx}}$ red areas incisal, blue areas cervical). A study with a significant number of samples would ensure the reciprocity between FEA and holographic measurements, based on the elastic properties of the materials (displacements, loads, Young's modulus).

Fig. 10 highlights the local strain changes computed from the displacement maps (Fig. 6) in the cervical region of the veneer. These changes are clearly revealed by $\varepsilon_{\mathrm{xx}}, \varepsilon_{\mathrm{yy}}$, and $\varepsilon_{\mathrm{xy}}$ maps. The $\varepsilon_{\mathrm{xy}}$ map also points out the accommodation of the applied load by the DCJ. The $\varepsilon_{\mathrm{xx}}$ 
$\varepsilon_{x x}(\mu \mathrm{m} / \mathrm{mm})$

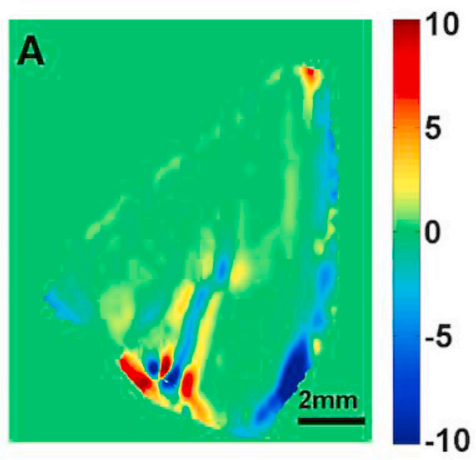

$\varepsilon_{x y}(\mu \mathrm{m} / \mathbf{m m})$

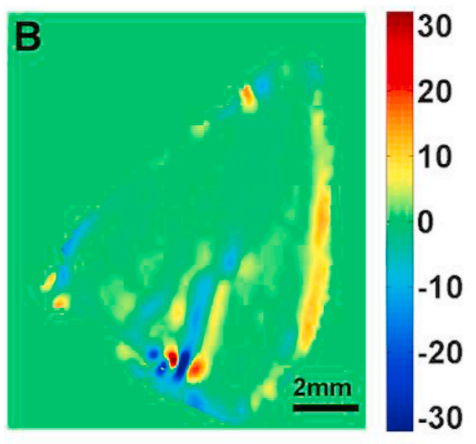

$\varepsilon_{\text {yy }}(\mu \mathrm{m} / \mathrm{mm})$

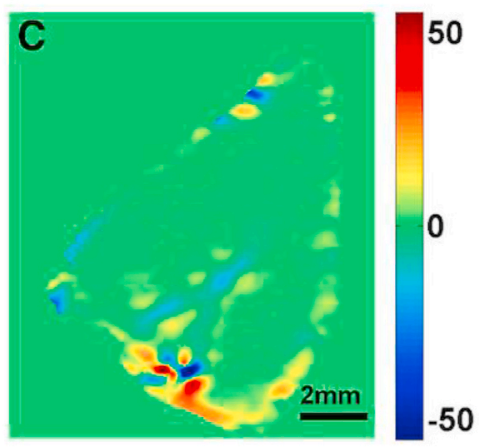

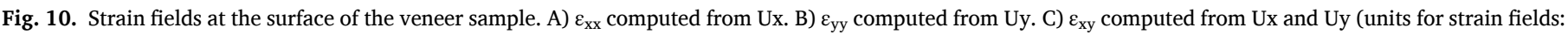
$\mu \mathrm{m} / \mathrm{mm})$.
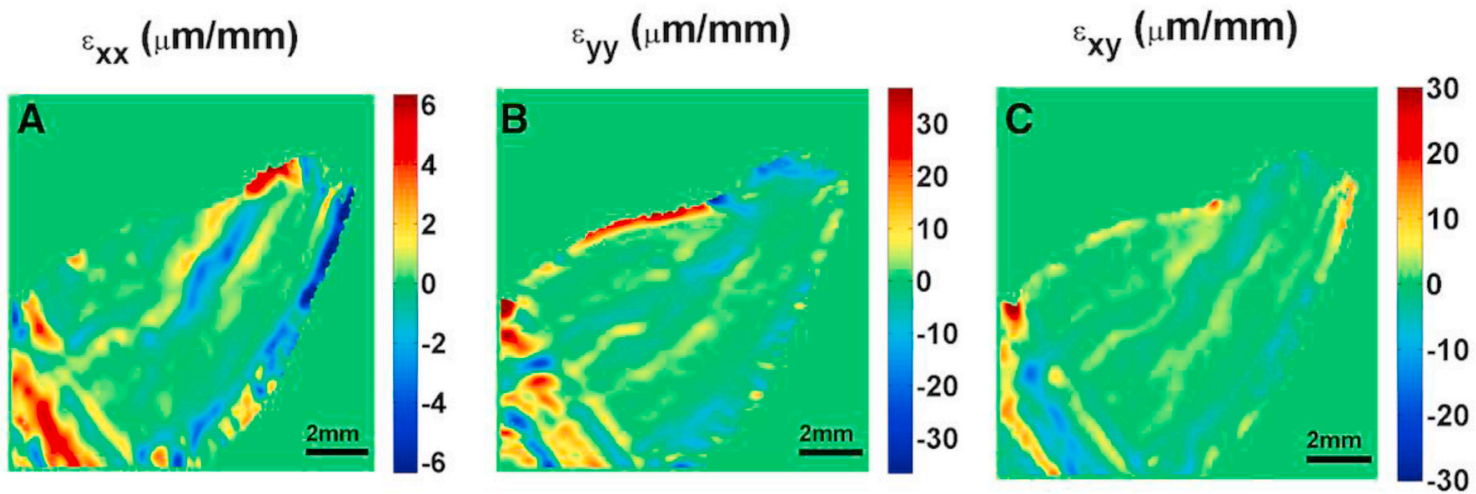

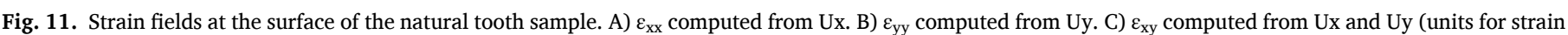
fields: $\mu \mathrm{m} / \mathrm{mm})$.

Table 1

Typical strain values for veneer tooth: maximum, minimum Peak to Valley (PV) and standard deviation $(\sigma)$.

\begin{tabular}{lll}
\hline$\varepsilon_{\mathrm{xx}}$ & $\varepsilon_{\mathrm{yy}}$ & $\varepsilon_{\mathrm{xy}}$ \\
\hline $\max : 17.02 \mu \mathrm{m} / \mathrm{mm}$ & $\max : 68.52 \mu \mathrm{m} / \mathrm{mm}$ & $\max : 39.59 \mu \mathrm{m} / \mathrm{mm}$ \\
$\min :-14.55 \mu \mathrm{m} / \mathrm{mm}$ & $\min :-92.26 \mu \mathrm{m} / \mathrm{mm}$ & $\min :-53.49 \mu \mathrm{m} / \mathrm{mm}$ \\
PV: $31.58 \mu \mathrm{m} / \mathrm{mm}$ & PV: $160.78 \mu \mathrm{m} / \mathrm{mm}$ & PV: $93.09 \mu \mathrm{m} / \mathrm{mm}$ \\
$\sigma: 2.21 \mu \mathrm{m} / \mathrm{mm}$ & $\sigma: 7.15 \mu \mathrm{m} / \mathrm{mm}$ & $\sigma: 4.43 \mu \mathrm{m} / \mathrm{mm}$ \\
\hline
\end{tabular}

Table 2

Typical strain values for natural tooth: maximum, minimum Peak to Valley (PV) and standard deviation $(\sigma)$.

\begin{tabular}{lll}
\hline$\varepsilon_{\mathrm{xx}}$ & $\varepsilon_{\mathrm{yy}}$ & $\varepsilon_{\mathrm{xy}}$ \\
\hline $\max : 8.84 \mu \mathrm{m} / \mathrm{mm}$ & $\max : 61.09 \mu \mathrm{m} / \mathrm{mm}$ & $\max : 50.15 \mu \mathrm{m} / \mathrm{mm}$ \\
$\min :-10.59 \mu \mathrm{m} / \mathrm{mm}$ & $\min :-47.17 \mu \mathrm{m} / \mathrm{mm}$ & $\min :-16.09 \mu \mathrm{m} / \mathrm{mm}$ \\
PV: $19.44 \mu \mathrm{m} / \mathrm{mm}$ & PV: $108.26 \mu \mathrm{m} / \mathrm{mm}$ & PV: $66.24 \mu \mathrm{m} / \mathrm{mm}$ \\
$\sigma: 1.55 \mu \mathrm{m} / \mathrm{mm}$ & $\sigma: 6.69 \mu \mathrm{m} / \mathrm{mm}$ & $\sigma: 3.6 \mu \mathrm{m} / \mathrm{mm}$ \\
\hline
\end{tabular}

map also shows increased activity with a switch from tensile to compression at the incisive face. This typical behavior is the warning sign of an important solicitation in the glue junction, causing an initiation of debonding between the veneer and the tooth caused by the applied force. The same behavior is shown by the $\varepsilon_{\mathrm{xx}}$ map presented in Fig. 10, with the highest activity at the cervical margin and confirmed by the dilation (red areas) - compression (blue areas) switch for $\varepsilon_{\mathrm{xx}}$

Granell-Ruiz et al. (Granell-Ruiz et al., 2014) studied the influence of bruxism on the survival of CLVs. The analysis of the ceramic failures showed that out of 13 fractures and 29 debondings that were recorded, 8 fractures and 22 debondings were related to bruxism. They concluded that a high risk of failure is present when the teeth of patients with bruxism are restored using ceramic laminate veneers. In theory, veneers should be subjected to a minimal occlusal load and therefore, it should only be used to reestablish esthetics and not function. However, veneers are not in contact with the opposite teeth. In fact, this paper highlights the influence of "pressure" forces on the bonding joint. Therefore, it is essential to understand how and where these forces are transmitted and how to neutralize them, or at least minimize them. As it has been previously shown, the DEJ accommodates the stress from the enamel to the dentin (Granell-Ruiz et al., 2014; Magne and Douglas, 1999b; Picart et al., 2019; Xia et al., 2018; Zaslansky et al., 2006) which is clearly shown in Fig. 11 where the $\varepsilon_{x y}$ shear is really smooth along the DEJ. There is also some visible compression in the $\mathrm{x}$-direction $\left(\varepsilon_{\mathrm{xx}}<0\right)$, and the typical change in tensile strain $\left(\varepsilon_{\mathrm{xx}}>0\right)$ is shown on the tip base of the natural tooth (Fig. 11). In the y-direction, $\varepsilon_{y y}$ is quasi-uniform. This confirms that if the veneer thickness is less than that of the enamel, the modulus of elasticity of the glue/cementing material should be close to enamel. However, the mechanical role of glue is negligible (Fages et al., 2012). The intact natural DEJ, which is still present, will then play a part in the natural accommodation of the stress. However, when the restoration extends to dentin, it is mandatory to use bonding agents with softer elasticity modulus matching with the one of DEJ (Fages et al., 2012; Xia et al., 2018).

Finally, the literature pertaining to debonding shows various fracture studies, or comparisons of fracture resistance versus tooth preparation. However, there are few publications on the behavior of the junction interface between the tooth and the veneer during stress. Digital 
holography allows this topic to be investigated, providing elements of response on detachment and the initiation of fractures by highlighting areas of stress concentrations, such as the $\varepsilon_{\mathrm{xx}}$ tensile on the veneer tip (red area; Fig. 10A) and the $\varepsilon_{\text {yy }}$ tensile on the veneer bottom shoulder (small orange-yellow area, Fig. 10C). In 2001, Seymour et al. (2001) in a mechanical study, investigated compressive and tensile stresses in composite and ceramic laminate veneer using different margin designs. When a labial load was applied, tensile stresses were as much as 25 times greater for the chamfer and shoulder designs compared with that of knife-edge design. Labial loading also resulted in an increase in tensile stresses within the composite lute and stresses were again lowest within the knife-edge margin design. Using the incisal overlap preparation, porcelain veneers with knife-edge labial margins could better sustain occlusal loading without undergoing fracture.

\section{Conclusion}

This paper demonstrates the application of digital color holography for comparative observation and analysis of the mechanical behavior of natural teeth and veneered teeth. To the best of our knowledge, the first application of digital color holography to measure strain fields for studying CLV is reported. The method applied to natural teeth and teeth restored using CAD/CAM ceramic veneer allows locating and interpreting stress concentrations for the different ROIs as at the interfaces such as bonding joint and DEJ, and can be used as a guide in the planning of the tooth preparation. As a result, for bonding of CLV to the enamel, the modulus of elasticity of the bonding material must be similar or close to that of the enamel. In addition, bonding of CLV to the dentin will require glue with much lower modulus of elasticity. From the analysis, the suggestion is that, for some clinical implications, using the form of tooth preparation that respects the anatomy of natural tooth (incisal overlap and chamfer labial margins) yields favorable distribution of strains. Further works will focus on other types of stress such as pressure or fatigue.

\section{Author statement}

Jean-Cédric Durand: Conceptualization, Writing-Review \& Editing. Pierre Slangen: Conceptualization, Formal analysis, Writing-Review \& Editing. Sylvio Montresor: Software, Validation, Formal analysis. Alban Desoutter: Methodology. Osama Yusuf Solieman: Methodology. Michel Fages: Conceptualization, Methodology, Writing-Review \& Editing. Pascal Picart: Conceptualization, Methodology, Software, Validation, Formal analysis, Writing-Review \& Editing.

\section{Funding}

This research did not receive any specific grant from funding agencies in the public, commercial, or not-for-profit sectors.

\section{Declaration of competing interest}

The authors declare that they have no known competing financial interests or personal relationships that could have appeared to influence the work reported in this paper.

\section{References}

Addison, O., Sodhi, A., Fleming, G.J., 2010. Seating load parameters impact on dental ceramic reinforcement conferred by cementation with resin-cements. Dent. Mater. 26, 915-921.

Archangelo, C.M., Rocha, E.P., Anchieta, R.B., Martin Jr., M., Freitas Jr., A.C., Ko, C.C., Cattaneo, P.M., 2011. Influence of buccal cusp reduction when using porcelain laminate veneers in premolars. A comparative study using 3-D finite element analysis. J. Prosthodont. Res. 55, 221-227.

Asundi, A., Kishen, A., 2001. Advanced digital photoelastic investigations on the toothbone interface. J. Biomed. Opt. 6, 224-230.
Asundi, A., Kishen, A., 2000a. Stress distribution in the dento-alveolar system using digital photoelasticity. Proc. Inst. Mech. Eng. 214, 659-667.

Asundi, A., Kishen, A., 2000b. A strain gauge and photoelastic analysis of in vivo strain and in vitro stress distribution in human dental supporting structures. Arch. Oral Biol. 45, 543-550.

Attia, A., Kern, M., 2004. Influence of cyclic loading and luting agents on the fracture load of two all-ceramic crown systems. J. Prosthet. Dent 92, 551-556.

Barak, M., Zaslansky, P., Shahar, R., Weiner, S., Friesem, A., 2006. Tooth and bone deformation: structure and material properties by ESPI. Proc. SPIE 6341. https://doi. org/10.1117/12.695264.

Barak, M.M., Geiger, S., Lev-Tov Chattah, N., Shahar, R., Weine, S., 2009. Enamel dictates whole tooth deformation: a finite element model study validated by a metrology method. J. Struct. Biol. 168, 511-520.

Calamia, J.R., 1983. Etched porcelain facial veneers: a new treatment modality based on scientific and clinical evidence. N. Y. J. Dent. 53, 255-259.

Ereifej, N., Rodrigues, F.P., Silikas, N., Watts, D.C., 2011. Experimental and FE shearbonding strength at core/veneer interfaces in bi-layered ceramics. Dent. Mater. 27, 590-597.

Fages, M., Slangen, P., Raynal, J., Corn, S., Turzo, K., Margerit, J., Cuisinier, F., 2012 Comparative mechanical behavior of dentin enamel and dentin ceramic junctions assessed by speckle interferometry. Dent. Mater. 28, 229-238.

Fages, M., Corn, S., Raynal, J., Slangen, P., Ienny, P., Cuisinier, F., Durand, J.C., 2017 Glass ceramic CAD/CAM crowns and severely altered posterior teeth: a three levels study. J. Mater. Sci. Mater. Med. 28, 145.

Feissel, P., 2012. From displacement to strain. In: Grediac, M., Hild, F. (Eds.), Full-field Measurements and Identification in Solid Mechanics. ISTE Wiley, London, p. 191.

Fratz, M., Beckmann, T., Anders, J., Bertz, A., Bayer, M., Gießler, T., Nemeth, C., Carl, D., 2019. Inline application of digital holography. Appl. Opt. 58, G120-G126.

Freydberg, B.K., 2011. No-prep veneers: the myths. Dent. Today 30, 70-71.

Ghiglia, D.C., Pritt, M.D., 1998. Two-dimensional Phase Unwrapping: Theory Algorithms, and Software, first ed. Wiley-Interscience.

Granell-Ruiz, M., Agustin-Panadero, R., Fons-Font, A., Roman-Rodriguez, J.L., SolaRuiz, M.F., 2014. Influence of bruxism on survival of porcelain laminate veneers. Med. Oral Patol. Oral Cir. Bucal 19, e426-e432.

Goodman, J.W., 1996. Introduction to Fourier Optics, second ed. McGraw-Hill Editions, New York.

Guarda, G.B., Gonçalves, L.S., Correr, A.B., Moraes, R.R., Sinhoreti, M.A., CorrerSobrinho, L., 2010. Luting glass ceramic restorations using a self-adhesive resin cement under different dentin conditions. J. Appl. Oral Sci. 18, 244-248.

Gür, E., Kesim, B., 2004. Porcelain laminate veneers. Cumhuriyet Univ. Dent. Faculty J, 7, 72-79.

Hong, N., Yang, H., Li, J., Wu, S., Li, Y., 2017. Effect of preparation designs on the prognosis of porcelain laminate veneers: a systematic review and meta-analysis. Operat. Dent. 42, E197-E213.

Horn, H.R., 1983. Porcelain laminate veneers bonded to etched enamel. Dent. Clin. North. Am. 27, 671-684.

Kemao, Q., Soon, S.H., Asundi, A., 2005. A simple phase unwrapping approach based on filtering by windowed Fourier transform. Opt Laser. Technol. 37, 458-462. https:// doi.org/10.1016/j.optlastec.2004.07.007.

Khodadad, D., Bergström, P., Hällstig, E., Sjödahl, M., 2015. Fast and robust automatic calibration for single-shot dual-wavelength digital holography based on speckle displacements. Appl. Opt. 54, 5003-5010.

Kishen, A., Asundi, A., 2007. Series on biomaterials and bioengineering. In: Fundamentals and Applications of Biophotonics in Dentistry, vol. 4. Imperial College Press, London.

Kishen, A., Tan, K.B., Asundi, A., 2006. Digital moiré interferometric investigations on the deformation gradients of enamel and dentine: an insight into non-carious cervical lesions. J. Dent. 34, 12-18.

Kishen, A., Asundi, A., 2002. Photomechanical investigations on post endodontically rehabilitated teeth. J. Biomed. Opt. 7, 262-270.

Kishen, A., Asundi, A., 2001. Investigations of thermal property gradients in the human dentine. J. Biomed. Mater. Res. 55, 121-130.

Kishen, A., Ramamurty, U., Asundi, A., 2000. Experimental studies on the nature of property gradients in the human dentine. J. Biomed. Mater. Res. 51, 650-659.

Kumar, M., Agarwal, R., Bhutani, R., Shakher, C., 2016. Measurement of strain distribution in cortical bone around miniscrew implants used for orthodontic anchorage using digital speckle pattern interferometry. Opt. Eng. 55, 054101.

Lev-Tov Chattah, N., Shahar, R., Weiner, S., 2009. Design strategy of minipig molars using electronic speckle pattern interferometry: comparison of deformation under load between the tooth-mandible complex and the isolated tooth. Adv. Mater. 21, 413-418.

Magne, P., Douglas, W.H., 1999a. Design optimization and evolution of bonded ceramics for the anterior dentition: a finite-element analysis. Quintessence Int. 30, 661-672.

Magne, P., Douglas, W.H., 1999b. Optimization of resilience and stress distribution in porcelain veneers for the treatment of crown-fractured incisors. Int. J. Periodontics Restor. Dent. 19, 543-553.

Meredith, N., Sheriff, M., Setchell, D., Sivanson, S., 1996. Measurements of the micro hardness and Young's modulus of human enamel and dentin using an indentation technique. Arch. Oral Biol. 41, 539-545.

Montresor, S., Picart, P., 2016. Quantitative appraisal for noise reduction in digital holographic phase imaging. Opt Express 24, 14322-14343.

Nejatidanesh, F., Savabi, G., Amjadi, M., Abbasi, M., Savabi, O., 2018. Five year clinical outcomes and survival of chairside CAD/CAM ceramic laminate veneers - a retrospective study. J. Prosthodont. Res. 62, 462-467. 
Ormenisan, A., Szava, D.T., Szava, I., Dalai, C., 2017. Mechanical stress exploration inside of dental filling materials by means of Electronic Speckle Pattern Interferometry/Shearography. Mater. Plast. 54 (4), 616-619.

Patel, N., 2014. Contemporary dental CAD/CAM: modern chairside/lab applications and the future of computerized dentistry. Comp. Cont. Educ. Dent. 35, 739-746.

Pedrini, G., Alekseenko, I., Jagannathan, G., Kempenaars, M., Vayakis, G., Osten, W., 2019. Feasibility study of digital holography for erosion measurements under extreme environmental conditions inside the International Thermonuclear Experimental Reactor tokamak. Appl. Opt. 58, A147-A155.

Peumans, M., Van Meerbeek, B., Lambrechts, P., Vanherle, G., 2000. Porcelain veneers: a review of the literature. J. Dent. 28, 163-177.

Picart, P., Leval, L., 2008. General theoretical formulation of image formation in digital Fresnel holography. J. Opt. Soc. Am. A25, 1744-1761.

Picart, P., 2015. New Techniques in Digital Holography. John Wiley \& Sons.

Picart, P., Fages, M., Slangen, P., Xia, H., Montresor, S., Guo, R., Li, J., Solieman, O.Y., Durand, J.C., 2019. A review on optical methods to assess dental behavior under stress. In: Proc. SPIE. 11060, Optical Methods for Inspection, Characterization, and Imaging of Biomaterials IV, 110600B. https://doi.org/10.1117/12.2531773.

Sasse, M., Krummel, A., Klosa, K., Kern, M., 2015. Influence of restoration thickness and dental bonding surface on the fracture resistance of full-coverage occlusal veneers made from lithium disilicate ceramic. Dent. Mater. 31, 907-915.

Schnars, U., Jüptner, W., 1994. Direct recording of holograms by a CCD target and numerical reconstruction. Appl. Opt. 33, 179-181.

Seymour, K.G., Cherukara, G.P., Samarawickrama, D.Y., 2001. Stresses within porcelain veneers and the composite lute using different preparation designs. J. Prosthodont. $10,16-21$.

Shahar, R., Weiner, S., 2007. Insights into whole bone and tooth function using optical metrology. J. Mater. Sci. 42, 8919-8933.

Silva, N.R., Calamia, C.S., Harsono, M., Carvalho, R.M., Pegoraro, L.F., Fernandes, C.A., Vieira, A.C., Thompson, V.P., 2006. Bond angle effects on micro tensile bonds: laboratory and FEA comparison. Dent. Mater. 22, 314-324.

St Germain Jr., H.A., St Germain, T.H., 2015. Shear bond strength of porcelain veneers rebonded to enamel. Operat. Dent. 40, E112-E121. https://doi.org/10.2341/14 123-L.
Tankam, P., Song, Q., Karray, M., Li, J.C., Desse, J.M., Picart, P., 2010. Real-time threesensitivity measurements based on three-color digital Fresnel holographic interferometry. Opt. Lett. 35, 2055-2057.

Üstün, O., Öztürk, A.N., 2018. The evaluation of stress patterns in porcelain laminate veneers with different restoration designs and loading angles induced by functional loads: a three-dimensional Finite Element Analysis study. Niger. J. Clin. Pract. 21, 337-342. https://doi.org/10.4103/njcp.njcp_45_17.

Wang, R., Weiner, S., 1998. Strain-structure relations in human teeth using Moiré fringes. J. Biomech. 31, 135-141.

Wood, J.D., Wang, R.Z., Weiner, S., Pashley, D.H., 2003. Mapping of tooth deformation caused by moisture change using Moiré interferometry. Dent. Mater. 19, 159-166.

Xia, H., Montresor, S., Guo, R., Li, J.C., Yan, F., Cheng, H., Picart, P., 2016. Phase calibration unwrapping algorithm for phase data corrupted by strong decorrelation speckle noise. Opt Express 24, 28713-28730.

Xia, H., Picart, P., Montresor, S., Guo, R., Li, J.C., Solieman, O.Y., Durand, J.C., Fages, M., 2018. Mechanical behavior of CAD/CAM occlusal ceramic reconstruction assessed by digital color holography. Dent. Mater. 34, 1222-1234.

Xu, H.H.H., Smith, D.T., Jahanmir, S., Romberg, E., Kelly, J.R., Thompson, V.P., Rekow, E.D., 1998. Indentation damage and mechanical properties of human enamel and dentine. J. Dent. Res. 77, 472-480.

Zahran, M., El-Mowafy, O., Tam, L., Watson, P.A., Finer, Y., 2008. Fracture strength and fatigue resistance of all-ceramic molar crowns manufactured with CAD/CAM technolog. J. Prosthodont. 17, 370-377.

Zaslansky, P., Currey, J.D., Friesem, A.A., Weiner, S., 2005. Phase shifting speckle interferometry for determination of strain and Young's modulus of mineralized biological materials: a study of tooth dentin compression in water. J. Biomed. Opt. 10, 024020.

Zaslansky, P., Friesem, A.A., Weiner, S., 2006. Structure and mechanical properties of the soft zone separating bulk dentin and enamel in crowns of human teeth: insight into tooth function. J. Struct. Biol. 153, 188-199.

Zheng, Z., Lin, J., Shinya, A., Matinlinna, J.P., Botelho, M.G., Shinya, A., 2012. Finite element analysis to compare stress distribution of gold alloy, lithium-disilicate reinforced glass ceramic and zirconia based fixed partial denture. J. Investig. Clin. Dent. 3, 291-307. 